1

\title{
Female mate choice based on territory quality in barn swallows
}

\author{
Running head \\ Female mate choice based on territory quality \\ Masaru Hasegawa ${ }^{1}$ (corresponding author), Emi Arai ${ }^{2}$, \\ Mamoru Watanabe ${ }^{1}$, \& Masahiko Nakamura ${ }^{2}$
}

${ }^{1}$ Graduate School of Life and Environmental Sciences, University of Tsukuba, Tsukuba, 1-1-1 Tennoudai, Tsukuba-shi, Ibaraki 305-8572, Japan

${ }^{2}$ Laboratory of Animal Ecology, Department of Biology, Joetsu University of Education, 1 Yamayashiki-machi, Joetsu-shi, Niigata 943-8512, Japan

Total text page 22

Number of tables 1

Number of figures 3 


\section{Female mate choice based on territory quality in barn swallows}

Abstract Female mate choice based on territory quality is difficult to study because territories often contain many resources, which are difficult to quantify. Here, using the barn swallow (Hirundo rustica gutturalis) breeding at an outdoor breeding site in Japan, where each male defend only a small territory containing old nests, we studied whether females choose social mates based on territory quality. Since the territories of this species contain few other resources, territory quality can easily be assessed by quantifying old nests in the territory. We made the following three observations: (1) Male swallows displayed old nests in their territories to females. (2) The old nests used for first clutch were less broken than the other old nests within the same territory. Territory quality, defined by the number of old nests weighted by the intactness of each old nest, predicted the productivity of the territory. (4) Males with better territories paired with females earlier, and hence bred earlier, than those with inferior territories. The relationships remained significant even after controlling for male morphological traits. Based on these results, we can infer that female swallows choose their mates based, in part, on territory quality.

Keywords: Hirundo rustica gutturalis, mate preference, mating advantage, old nests, territory choice. 


\section{Introduction}

For bird species in which males defend breeding territories, females may choose mates based on male phenotype and/or territory characteristics (e.g., Alatalo et al., 1986; Buchanan \& Catchpole, 1997; Marchetti, 1998; Eckerle \& Thompson, 2006; reviewed in Andersson, 1994; Jennions et al., 1997; Candolin, 2003). Among such species, there have been many studies on female mate choice for male phenotype, because this promotes intersexual selection (Andersson, 1994). Female mate choice for territory characteristics should also facilitate sexual selection by promoting male-male competition and indirect mate choice (Wiley \& Poston, 1996). However, female mate choice based on territory quality is less well studied owing to the difficulty of measuring territory quality in species with all-purpose territories containing many resources that are difficult to quantify (e.g., vegetation type and density, perch site, food, and nest site; Searcy \& Yasukawa, 1995).

The barn swallow (Hirundo rustica) is a monogamous species in which each male defend only a small territory, which usually contain old nests constructed in previous seasons (reviewed in Møller, 1994; Turner, 2006). After pairing, pairs often repair old nests and use them as breeding nests, although they can also construct new nests (Møller, 1994). Since their territories contain few other resources, territory quality can easily be assessed by quantifying old nests in the territory. Individual old nests were in fact assessed by females or settling pairs and old nests of high quality were reported to be preferred (e.g., fewer mites; Barclay, 1988; Møller, 1990a; Safran, 2006), indicating that old nests are important resources for breeding. However, previous studies have been focused on nest choice but not on mate choice based on territory quality. It should be noted that nest choice is not equivalent to mate choice in this species. For example, even without mate choice, nest choice can be explained, because females can choose nests within territories which often contain multiple old nests or 
nest sites in this species (cf. Barclay, 1988; the current results). In addition, nest choice can be done after pairing (cf. Møller, 1990a), which by definition does not accompany mate choice. Settling pairs may choose old nests which are not occupied by other birds. Therefore, it remains unclear whether individual males are chosen based on territory quality in the population or breeding site (but see Safran, 2007 for the influence of breeding site selection on mate choice).

Møller (1990b) has indirectly investigated the importance of territory quality for female mate choice from correlation analysis of settlement patterns of males in different years. The prediction is that arriving males should tend to occupy the same territories first each year if territory quality is important in determining female choice. This prediction rests on the assumption that the quality of territories remains unaltered during the period of study, as seems to be the case in his study area (Møller, 1994). Since the correlation between settlement orders in different years was low and non-significant even after excluding males that have already bred once in a study site (Møller, 1990b), he argued that territory quality is unimportant for female mate choice in barn swallows.

However, choosing a male as a function of the territory he is defending has three potential advantages, even if territories contain few resources other than old nests. First, since the old nests constructed in previous breeding seasons can persist and indicate past reproductive success in the territory (Safran, 2004; Turner, 2006), it would be beneficial for females to choose a breeding site based on old nests for successful breeding (Shields et al., 1988; see also Erckmann et al., 1990; Gergely et al., 2009). Indeed, Safran $(2004,2007)$ shows that female swallows prefer to breed in colonies containing many old nests, suggesting the importance of old nests as an indicator of breeding site quality. Second, by using old nests, females can save time by not having to build a new nest (reviewed in Turner, 2006). Although the time saving may be a small part of the whole season, starting each brood as early as possible may help improve the 
long-term survival of the chicks and thus their chances of recruiting into the population (Turner, 2006; Grüebler \& Naef-Daenzer, 2010). Early breeders are also more likely to have time for a second brood (Møller, 1994). In addition, since the re-use of old nests necessitates fewer trips to collect nesting materials, it can also reduce the risk of predation and saves energy (cf. Withers, 1977). More intact the old nest is used, more time and energy will be saved. Third, the presence of multiple old nests in a territory, which is often seen in outdoor breeding sites (compared with indoor breeding sites such as stables), may be an additional advantage for females choosing a male territory, since multiple nests may lead to a dilution effect in predation risk (cf. Watts, 1987; Searcy \& Yasukawa, 1995). Multiple old nests might also be an option to breed a second clutch when the breeding nest used for a first clutch should not be used for a second clutch (e.g. increased parasite load: Møller, 1990a). Hence, we predict that female swallows choose their mates based on the intactness and quantity of old nests in male territories.

Old nests entailed potential costs, too. Increased ectoparasite infestation and falling nests were reported to be such costs in this species, both of which increase nestling mortality (Shields \& Crook, 1987; Møller, 1990a). However, the costs of ectoparasite infestation and nest falling would not outweigh the potential benefits stated above (cf. Safran, 2006). In our study population at Joetsu city in Japan, most nest failure were from nest predation, and nestling death due to heavy infestation and nest falling were rarely found (Tajima \& Nakamura, 2003; Hasegawa, 2005; M. Hasegawa, unpublished data), supporting Safran's point of view.

Here, we studied female mate choice based on territory quality in barn swallows nesting in an outdoor breeding site. For this purpose, we studied (i) male courtship behavior, in which important criteria of female mate choice must be shown by males (cf. Searcy \& Yasukawa, 1995); (ii) nest choice within territories; (iii) the predictability of the previous productivity in territory; (iv) the relationship between breeding date (pairing date and laying date) and territory quality, defined by the number 
of old nests weighted by the intactness of each old nest. The barn swallow is a model species for studying female mate choice or similar intersexual selection process on male phenotypes (morphological traits including coloration; Møller, 1988; Safran \& McGraw, 2004; body condition; Kojima et al., 2009; male nest building behaviour after pairing; Soler et al., 1998). Thus, we also investigated (v) whether female mate choice based on territory quality was confounded by male morphology including four ornaments (tail length, white spots in the tail, throat coloration, throat patch size), which might be targets of female choice in our population (Hasegawa et al., 2010a, b).

\section{Materials \& methods}

\section{Study site and observations}

This study was conducted in March to August 2007 in a residential area of Joetsu City, Niigata Prefecture, Japan $\left(37^{\circ} 07^{\prime} \mathrm{N}, 138^{\circ} 15^{\prime} \mathrm{E} ; 10 \mathrm{~m}\right.$ asl.), where the swallows nest under the eaves of a covered sidewalk along the street and breed in a loose colony (cf. Tajima \& Nakamura, 2003). We inspected nests every other day to record breeding events. This allowed us to determine the laying date, which was expressed as the date of clutch initiation. Laying date can be used as an indicator of female mate choice (cf. Andersson, 1994; Møller, 1994). Since laying date may be influenced by a number of factors other than female choice (e.g., female quality, time required for repairing old nests, weather conditions between mating and egg laying), we also used a more direct indicator of female choice, namely, pairing date, using previously marked birds. Pairing date was defined as the first day the pair was seen together by daily observation. By daily observation, we also recorded arrival date of males (cf. Arai et al., 2009), which may be confounded with the relationship between pairing date and territory quality. 
We observed each unmated male for at least one hour in front of its territory using a video camera-recorder (SONY CCD-TRV92). A total of 251 courtship displays performed by 43 unmated males (number of display for each individual, mean $\pm \mathrm{SD}=5$ \pm 6 ; total observation hour: $93 \mathrm{~h}$ ) were observed from late March to early May.

Measuring territory quality

In the current study, a territory was defined as the eave of one house. This is because the preliminary study showed that it was rare for more than one pair of swallows to breed under each eave in our study site (3 out of 111 in 2005 and 4 out of 97 in 2006; M. Hasegawa, unpublished data). In 2007, all but one eave had a single breeding pair (after pair formation, one pair migrated from their original territory to an eave where another pair was already breeding, probably because of human disturbance). Each eave across the study site has a similar area (ca. 10-15 $\mathrm{m}^{2}$ ). Before the arrival of the birds, all the nests in the study area were scored according to one of the following five categories: 1 - trace of old nest with little mud remaining; 2-small mass of mud remaining; 3 -approximately half of the old nest remaining; 4-old nest with some damage; 5 -old nest with little damage. Although categories 1 and 2 are rarely treated as old nests in previous studies, even these 'scars' would offer important information to females making decisions about where to breed (Shield et al., 1988; Safran, 2004). Territory quality was defined by the number of old nests weighted by the intactness of each old nest (i.e. if territory includes two old nests, scored 3 and 4, respectively, territory quality was $1 \times 3+1 \times 4=7$ ). When multiple nests were found clinging together, we classified these as a single old nest and assigned it the score of the individual nest with the highest score. The reason why we used the number weighted by the intactness of each old nest is that we predicted that intactness would have influence on female choice (see Introduction section). In fact, the preliminary analyses showed that all the relationships were stronger when we used weighted sum rather than when we used the number of old nests itself. Weighted sum might not be a good measure when there are 
many territories with many broken (i.e. score 1 or 2 ) old nests (e.g. $2+2+2+2+2$ ),

189 because the quality of such territories is judged better than the territories containing an 190 old nest with little damage (scored 5). However, these cases were very rare in the 191 current sample, because all territories except for three $(2+2+2+2,1+1+1+1+2$, and $1921+1+2)$ include less than three broken nests $(\mathrm{N}=67)$. Moreover, the analyses excluding 193 the three territories provides qualitatively similar significant results, indicating that the influence of these cases were small. Although the above argument was based on the assumption that territories including an old nest with little damage must be better quality than territories with many broken old nests, we could not know the relative importance of intactness and quantity of old nests. Thus, we presented the analyses including the three males. Since all the three territories were held by age-unknown males, the analyses of ASY (see below) males include no such cases.

Productivity of territory

To know the predictability of productivity by the territory quality, we investigated the relationship between territory quality and the total number of fledgling in the territory during the previous season. For this purpose, we used territories which were occupied in both 2006 and 2007. In addition, we studied the relationship between territory quality and the number of successful clutches and mean fledglings per clutch.

Capture and measurement of birds

Adults were captured using sweep nets while roosting at night. Birds were fitted with a numbered aluminum ring and an individual combination of two or three colored rings (cf. Arai et al., 2009). The sex of an individual was determined by the presence (female) or absence (male) of an incubation patch. Adults were placed into two groups-ASY (after second year) birds and age-unknown birds — based on ringing records. Nest ownership was subsequently determined using binoculars. 
throat patch height, and collected some throat feathers. Tail length was defined as the right outermost tail feather and was measured to the nearest $0.01 \mathrm{~mm}$. The size of the white spots in the tail was defined as the sum of the length of the white spots of the 2 outermost tail feathers on the right side (Hasegawa et al., 2010a, b). We also recorded male body weight. Although the previous study used body condition, defined as a residual from regression of the body weight to tarsus length (Kojima et al., 2009; Hasegawa et al., 2010a), we used body weight itself as a variable because of no significant relationship between body weight and tarsus length in the current sample ( $N$ $=25, r=0.12, p=0.56)$.

Throat patch height was defined as the height of the swallow's red throat patch. We used throat patch height rather than throat patch area in the current study for ease in measurement. We placed a transparent plastic sheet on the throat region, ensuring that the feathers lay flat in their natural position, and traced the size of the patch on the sheet with a marker pen (cf. Lendvai et al., 2004). We scanned the sheet and measured the height of the patch (in millimeters) by using Scion Image software (Scion Corporation, Frederick, MD). For each bird, throat patch was traced twice and the mean of the 2 measurements was used. The detailed method is described elsewhere (Hasegawa et al., 2010a).

Once in the laboratory, we piled five feathers on a piece of white paper so that the perimeters of the feathers coincided. The feather samples were scanned at 800-dpi resolution by using an EPSON GT 9300 UF scanner, and the images obtained were imported into the Adobe Photoshop Elements 3.0 program (Adobe Systems, USA). We measured mean RGB values in a square of 30 pixels near the distal end of the feather sample. The mean RGB values were converted to hue-saturation-brightness (HSB)-values by the algorithm described by Foley \& van Dam (1984). Among these three color variables, saturation value is taken as the representative of plumage coloration, because this variable does not need to be corrected for plumage color fading 
(Hasegawa et al., 2008). The detailed method is described elsewhere (Hasegawa et al., 2008, 2010a). RGB color systems and subsequent conversion into HSB is commonly used for measuring feather coloration, especially when there is no reflectance in ultraviolet region (reviewed in Hill \& McGraw, 2006), which is also the case in the throat feathers of barn swallows (Safran \& McGraw, 2004; M Hasegawa, unpublished data).

\section{Statistical procedures}

To compare the nest scores between a used nest for first clutch and the other old nests within each territory, we used a liner mixed-effect model (LME) using the function lme (package nlme) in the R statistical package (version 2.8.0; R Development Core Team, 2008). This is similar procedure with paired $t$-test, but can compare more than two nests within each territory differed with paired $t$-test. Since the data were overdispersed, we used a general linear model (GLM) using a quasi-poisson error distribution and a log link function to investigate pairing date and laying date in relation to territory quality. Among the breeding pairs, only one pair bred in a territory without old nests (1/84). We excluded this pair from the analysis, although their inclusion did not affect the results. This pair was excluded from the analysis so as not to confound the quantitative difference of old nests in the territory with the effect of the presence of old nests. Since laying date is known to be affected by male age, analyses were also conducted using only ASY males to distinguish the effect of male age from that of territory quality itself. Since laying date may be affected by male morphological traits, analyses were also conducted after statistically controlling for significant effects of male morphological traits. We obtained pseudo- $R^{2}$ values (in the following simply referred to as $R^{2}$ ) as a measure of variance accounted for by the model (Heinzl \& Mittlböck, 2003). All data analyses were performed using the $\mathrm{R}$ statistical package. 


\section{$273 \quad$ Results}

Among 251 courtship displays observed, most males commenced courtship in the air $(\mathrm{N}$ $=208)$ while the others started courting on telegraph wires $(N=43)$. Secondly, they led females to an old nest or to a potential nest site $(\mathrm{N}=182)$, which contained no old nest but could be used to construct a new nest, emitting typical "wie-wie-wie" notes (cf. Turner, 2006). Thirdly, approximately one-half of the males that successfully led females to a nest (34 out of 69) were also observed to sequentially show females other nests in their territories.

Nest choice within a territory

Each territory contained $2.09 \pm 1.04$ old nests (mean $\pm \mathrm{SD}$; range $=1-5$ nests; $N=67$ )

When the nest scores of nests used for first clutch among pairs that had at least two old nests in their territory were compared with the scores of the other old nests within the same territory, old nests used for first clutch were found to have significantly higher scores (LME: the random factor is territory ID; $N_{\text {territory }}=36, N_{\text {nest }}=91$, Coef $\pm \mathrm{SE}=$ $0.77 \pm 0.30, t=2.54, p=0.01)$.

Territory quality and productivity

Population means of territory quality, defined by the number of old nests weighted by the intactness of each old nest was $7.45 \pm 3.57$ (mean $\pm \mathrm{SD}$, range from 2 to $18 ; N=67$ ). Territory quality was positively correlated with the total number of fledglings in the territory during the previous year $\left(N=47\right.$, Spearman's rank correlation coefficient, $r_{s}=$ 

outlier $\left(N=46, r_{s}=0.41, p<0.01\right)$. The significant relationship derived from the positive relationship between territory quality and the number of successful clutches (range from 0 to $2 ; N=47, r_{s}=0.55, p<0.01$ ). There was no significant relationship between territory quality and mean fledgling number per clutch (range from 0 to $5 ; N=$ $\left.47, r_{s}=0.11, p=0.48\right)$.

Territory quality and laying date

There was a negative relationship between territory quality and laying date $(N=67$, Coef $\pm \mathrm{SE}=-0.07 \pm 0.03, F=8.90, R^{2}=0.11, p=0.004$; open and filled circles and broad regression curve in Figure 2). Since there were effects of male age on laying date (ASY males: $N=22$, median $=20$ April, range $=12$ April to 8 May; age-unknown males: $N=58$, median $=2$ May, range $=13$ April to 8 June; Mann-Whitney $U$-test, $z=$ $3.85, p<0.0001$ ) and on territory quality (ASY males: $N=21$, mean $\pm \mathrm{SE}=9.0 \pm 0.8$; age-unknown males: $N=46$, mean $\pm \mathrm{SE}=6.8 \pm 0.5$; Mann-Whitney $U$-test, $z=2.52, p$ $=0.01$ ), age effects might have confounded the results. However, this was not the case, because the effect of territory quality remained even after excluding males whose age was not known (GLM with quasi-poisson distribution: $N=21$, Coef $\pm \mathrm{SE}=-0.12 \pm 0.04$, $F=10.74, R^{2}=0.29, p=0.004$; filled circles and narrow regression curve in Figure 2). This relationship remained significant even when using males that did not reunite with their mate of the previous year (GLM with quasi-poisson distribution: $N=14$, Coef $\pm \mathrm{SE}$ $\left.=-0.13 \pm 0.05, F=7.66, R^{2}=0.36, p=0.02\right)$.

In ASY males, it is possible that females use the productivity of territory directly by observing fledgling number in the previous years instead of using territory quality which is an indirect indicator of the productivity. Thus, we studied the relationship between the productivity of the territory during the previous year and laying 
date. However, laying date was not significantly related to the total number of fledglings in the territory during the previous year and laying date (GLM with quasi-poisson distribution; $N=16, \operatorname{Coef} \pm \mathrm{SE}=-0.01 \pm 0.09, F=0.02, R^{2}=-0.07, p=$ 0.90 ), nor the number of successful clutches (GLM with quasi-poisson distribution; $N=$ 16 , Coef $\pm \mathrm{SE}=-0.13 \pm 0.31, F=0.17, R^{2}=-0.06, p=0.69$ ).

\section{Territory quality and pairing date}

We also found a negative relationship between pairing date and territory quality in ASY birds (GLM with quasi-poisson distribution: $N=18, \operatorname{Coef} \pm \mathrm{SE}=-0.18 \pm 0.07, F=9.29$, $R^{2}=0.30, p=0.007$; Figure 3 ). This relationship remained significant even when using males that did not reunite with their mate of the previous year (GLM with quasi-poisson distribution: $\left.N=13, \operatorname{Coef} \pm \mathrm{SE}=-0.16 \pm 0.07, F=6.81, R^{2}=0.28, p=0.02\right)$. There was a similar relationship between pairing date and territory quality after controlling for arrival date (GLM with quasi-poisson distribution: $N=18$; territory quality: Coef $\pm \mathrm{SE}=$ $-0.15 \pm 0.07, F=5.52, p=0.03$; arrival date: $\mathrm{Coef} \pm \mathrm{SE}=0.06 \pm 0.03, F=4.03, p=$ 0.06 ; overall model: $F=7.11, R^{2}=0.40, p<0.01$ ), indicating that differential arrival date was not confounded with the significant relationship between territory quality and pairing date. Among the 18 males for which the pairing date was known, four males changed their territory before their mating status was confirmed (i.e., unmated or mated). Hence, it is possible that some of these birds changed breeding territory after pair formation. However, excluding these four birds did not alter the relationship between pairing date and territory quality (GLM with quasi-poisson distribution: $N=14$, Coef \pm $\left.\mathrm{SE}=-0.18 \pm 0.05, F=13.62, R^{2}=0.46, p=0.003\right)$. This was also the case when controlling for the effect of arrival date (GLM with quasi-poisson distribution; $N=14$; territory quality: $\operatorname{Coef} \pm \mathrm{SE}=-0.14 \pm 0.06, F=7.29, p=0.02$; arrival date: $\mathrm{Coef} \pm \mathrm{SE}=$ $0.03 \pm 0.02, F=1.94, p=0.19$; overall model: $\left.F=7.95, R^{2}=0.50, p<0.01\right)$. 

the territory during the previous year (GLM with quasi-poisson distribution; $N=12$, Coef $\left.\pm \mathrm{SE}=-0.02 \pm 0.14, F=0.03, R^{2}=-0.08, p=0.87\right)$ and the number of successful clutches (GLM with quasi-poisson distribution; $N=12$, Coef $\pm \mathrm{SE}=-0.26 \pm 0.52, F=$ $\left.0.24, R^{2}=-0.07, p=0.63\right)$, although sample sizes were small.

The influence of male morphology

Among seven male morphological traits, wing length, tail length, and white spots in the tail were significantly correlated with laying date (Table 1). Thus, the relationship between laying date and territory quality might be confounded by these variables. However, this might not be the case, because territory quality remained significant even after controlling for these three significant terms separately or in combination (territory quality: $N=31$, Coef $>-0.08, F>5.29, p<0.03)$. correlated with laying date (Table 1). Thus, male morphology might not be confounded with the significant relationship between territory quality and laying date in ASY males. This was also the case for the analysis of pairing date (Table 1).

\section{Discussion}

In this study, we showed that males displayed old nests to females during their courtship behavior, suggesting the importance of old nests in attracting potential mates. Within territories, more intact old nests were used as breeding nests. Territory quality, defined by the number of old nests weighted by the intactness of each old nest, provided information about the productivity of the territory (Figure 1). Males having many intact old nests in their territory bred earlier than others (Figures $2 \& 3$ ). These results are 
consistent with the idea that female barn swallows chose their social mates, in part, based on territory quality. Since we used the intactness of old nests as the criterion of territory quality, the early laying date in good territories may be attributable to the fact that pairs in these territory spend less time repairing old nests before laying a clutch than those in less good territories (e.g., Turner, 2006; Safran, 2006). However, this explanation could not account for the early mating date of males with good territories (Figure 3). The alternative explanation that females chose territory indirectly from male ornaments might not be the case, because female mate choice based on territory quality remains significant after controlling for male ornaments. These analyses could not deny the possibility that territory quality was correlated with some other male traits (e.g. song, courtship performance), which was directly chosen by females. However, even in these cases, females indirectly chose males based on territory quality as a result. Thus, we conclude that female swallows choose their mates based on territory quality.

Our finding is inconsistent with the argument that territory quality is unimportant for mate choice in barn swallows in another population (Møller, 1990b, 1994). Møller's argument is based on the observation that the correlation between settlement orders in different years was low and non-significant, which should be positively correlated if territory quality is important. However, his argument rests on some assumptions (see Introduction section; see also Møller, 1994) and is not a necessary condition for female mate choice based on territory quality. Thus, although their study did not find evidence of female mate choice for territory quality, we could not determine whether the difference in conclusion between Møller's and ours is for the difference of methodology or population difference in female behavior itself (see below). Anyway, to the best of our knowledge, the current study is the first to show female mate choice based on territory quality in barn swallows. This study reinforces the previous finding that females or settling pairs choose their breeding site (colony choice: Safran, 2004, 2007; breeding nests: Barclay, 1988; Møller, 1990a; Safran, 2006), 
and further demonstrates that females use similar criteria when choosing their mates. Since old nests provide several benefits, all of which increased fitness of females, and some costs (reviewed in Introduction; Turner, 2006), it might be beneficial for females to choose proper breeding site when choosing nest and colony themselves as well as choosing males having different quality of territories.

As shown in this study, even females of a species that has few resources other than nests within its territory choose their mates based on territory quality. Female mate choice based on territory quality, measured by nest-site quality, has also been shown in certain other species (e.g., pied flycatcher: Slagsvold, 1986; house sparrow: Møller, 1988). Thus, territories containing few resources other than nests should not simply be assumed to be unimportant, which has been the case in some studies (e.g., Møller, 1994; Carty et al., 1999; Friedl \& Klump, 1999). Rather, since the measure of nest site, such as the quality of old nests, can be easily quantified both by observers and birds and was often used for nest site choice (e.g. Erckmann et al., 1990; Antonov \& Atanasova, 2003; Mazgajski, 2007; Gergely et al., 2009), species with territory which include few resources other than nests should be used as model species to study female mate choice based on territory quality.

Here, we showed female mate choice based on territory quality in the barn swallow, which is a model species for sexual selection (Møller, 1994). Sexual selection studies for male ornaments in this species have focused exclusively on female mate choice (reviewed in Møller, 1994). However, female mate choice based on territory quality was relatively more important than male ornaments in the given environment and thus could have an influence on sexual selection by promoting male-male competition and indirect mate choice for male phenotype (Wiley \& Poston, 1996). Sexual selection studies should take territory quality into consideration to know how the selection works on male phenotype, which is beyond our scope here. In addition, the intensity and direction of female mate choice based on territory quality may vary among 
populations, which is predicted from geographic variation in the relative importance of benefits and costs of old nests (e.g. the importance of ectoparasite would differ among populations; Barclay, 1988; Safran, 2006). It remains to be determined whether female mate choice based on territory quality varies across species range and its influence on the geographic variation in sexual selection and ornamentation.

Acknowledgements We are grateful to the residents of Joetsu City for their kind support and assistance. This manuscript benefited from comments by R. J. Safran. We also thank the members of the Laboratory of Animal Ecology of Joetsu University of Education and the Laboratory of Conservation Ecology of University of Tsukuba.

\section{References}

Alatalo RV, Lundberg A, Glynn C (1986) Female pied flycatchers choose territory quality and not male characteristics. Nature 323:152-153

Andersson M (1994) Sexual selection. Princeton University Press, Princeton

Antonov A, Atanasova D (2003) Re-use of old nests versus the construction of new ones in the Magpie Pica pica in the city of Sofia (Bulgaria). Acta Ornithol $38: 1-4$

Arai E, Hasegawa M, Nakamura M (2009) Divorce and asynchronous arrival in Barn Swallows Hirundo rustica. Bird Study 56:411-413

Barclay RM (1988) Variation in the costs, benefits, and frequency of nest reuse by Barn Swallows (Hirundo rustica). Auk 105:53-60

Buchanan K, Catchpole C (1997) Female choice in the sedge warbler, Acrocephalus schoenobaenus: multiple cues from song and territory quality. Proc R Soc Lond B 264:521-526

Candolin U (2003) The use of multiple cues in mate choice. Biol Rev 78:575-595 
Catry P, Phillips RA, Furness R (1999) Evolution of reversed sexual size dimorphism in skuas and jaegers. Auk 116:158-168

Eckerle KP, Thompson CF (2006) Mate choice in house wrens: nest cavities trump male characteristics. Behaviour 143:253-271

Erckmann WJ, Beletsky LD, Orians GH, Johnsen T, Sharbaugh S, D’Antonio C (1990) Old nests as cues for nest-site selection: an experimental test with red-winged blackbirds. Condor 92:113-117

Foley JD, van Dam A (1984) Intensity and color. In: Fundamentals of Interactive Computer Graphics. Addison-Wesley, Philippines, pp 593-622

Friedl TWP, Klump GM (1999) Determinants of male mating success in the red bishop (Euplectes orix). Behav Ecol Sociobiol 46:387-399

Gergely Z, Mészáros A, Szabad J, Székely T (2009) Old nests are cues for suitable breeding sites in the Eurasian penduline tit Remiz pendulines. J Avian Biol $40: 2-6$

Grüebler M U, Naef-Daenzer B (2010) Fitness consequences of timing of breeding in birds: data effects in the course of a reproductive episode. J Avian Biol 41:282-291

Hasegawa M (2005) Nihonno tsubame ni okeru seisentaku keisitu. —MS Thesis, University of Tsukuba, Tsukuba, Japan (In Japanese)

Hasegawa M, Arai E, Watanabe M, Nakamura M (2008) Methods for correcting plumage color fading in the Barn Swallow. Ornithol Sci 7:117-122

Hasegawa M, Arai E, Watanabe M, Nakamura M (2010a) Mating advantage of multiple male ornaments in the Barn Swallow Hirundo rustica gutturalis. Ornithol Sci 9:141-148

Hasegawa M, Arai E, Kojima W, Kitamura W, Fujita G, Higuchi H, Watanabe M, Nakamura M (2010b) Low level of extra-pair paternity in a population of the Barn Swallow Hirundo rustica gutturalis. Ornithol Sci 9:161-164 
Heinzl H, Mittlbock M (2003) Pseudo $R$-squared measures for Poisson regression models with over- or underdispersion. Computational Statistics and Data Analysis 44:253-271

Hill GE, McGraw KJ (2006) Bird coloration. I. Mechanisms and measurements. Harvard Univ. Press, Cambridge.

Kojima W, Kitamura W, Kitajima S, Ito Y, Ueda K, Fujita G, Higuchi H (2009) Female barn swallows gain indirect but not direct benefits through social mate choice. Ethology 115:939-947

Jennions MD, Petrie M (1997) Variation in mate choice and mating preferences: a review of causes and consequences. Biol Rev 72:283-327

Lendvai AZ, Kis J, Szekely T, Cuthill IC (2004) An investigation of mate choice based on manipulation of multiple ornaments in Kentish plovers. Anim Behav 67:703-709

Marchetti K (1998) The evolution of multiple male traits in the yellow-browed leaf warbler. Anim Behav 55:361-376

Mazgajski TD (2007) Effect of old nest material on nest site selection and breeding parameters in secondary hole nesters ? a review. Acta Ornithol 42:1-14

Møller AP (1988) Badge size in the house sparrow Passer domesticus. Behav Ecol Sociobiol 22:373-378

Møller AP (1990a) Effects of parasitism by a haematophafous mite on reproduction in the barn swallow. Ecology 71: 2345-2357

Møller AP (1990b) Male tail length and female mate choice in the monogamous swallow Hirundo rustica. Anim Behav 39:458-465

Møller AP (1994) Sexual selection and the barn swallow. Oxford University Press, Oxford

R Development Core Team (2008) R: A language and environment for statistical computing. R Foundation for Statistical Computing, Vienna, Austria. ISBN 
Safran RJ (2004) Adaptive site selection rules and variation in group size of barn swallows: individual decisions predict population patterns. Amer Natur

Safran RJ (2006) Nest-site selection in the barn swallow, Hirundo rustica: What predicts seasonal reproductive success? Can J Zool 84:1533-1539

Safran RJ (2007) Settlement patterns of female barn swallows Hirundo rustica across different group sizes: access to colorful males or favored nests? Behav Ecol Sociobiol 61:1359-1368

Safran RJ, McGraw KJ (2004). Plumage coloration, not length or symmetry of tail-streamers, is a sexually selected trait in North American barn swallows. Behav Ecol 15:455-461

Searcy WA, Yasukawa K (1995) Polygyny and Sexual Selection in Red-winged Blackbirds. Princeton University Press, Princeton

Shields WM, Crook JR (1987) Barn swallow coloniality: a net cost for group breeding in the Adirondacks? Ecology 68:1373-1386

Shields WM, Crook JR, Heibblethwaite ML, Wiles-Ehmann SS (1988) Ideal free coloniality in the swallows. In: Slobodchikoff CN (ed) The Ecology of Social Behavior. Academic Press, San Diego, pp 189-228

Slagsvold T (1986) Nest site settlement by the Pied Flycatcher: does the female choose her mate for the quality of his house or himself? Ornis Scand 17:210-220

Soler JJ, Cuervo JJ, Møller AP, De Lope F (1998) Nest building is a sexually selected behaviour in the barn swallow. Anim Behav 56: 1435-1442

Tajima K, Nakamura M (2003) Response to manipulation of partner contribution: A handicapping experiment in the Barn Swallow. Ornithol Sci 2: 65-72

Turner AK (2006) The Barn Swallow. T \& AD Poyser, London

Watts BD (1987) Old nest accumulation as a possible protection mechanism against 
543 Wiley RH, Poston J (1996) Indirect mate choice, competition for mates, and $544 \quad$ coevolution of the sexes. Evolution 50:1371-1381

545 Withers PC (1977) Energetic aspects of reproduction by the Cliff Swallow. Auk 546 94:718-725

547 
Table 1 Simple GLM with quasipoisson distribution between male morphological traits and the laying date (12

April $=0)$ of his mate and pairing date $(31 \mathrm{March}=0)$ of his mate.

\begin{tabular}{lcccccc}
\hline & \multicolumn{2}{c}{ Laying date (All males) } & \multicolumn{2}{c}{ Laying date (ASY males) } & \multicolumn{2}{c}{ Pairing date (ASY males) } \\
& Coefficient & $R^{2}$ & Coefficient & $R^{2}$ & Coefficient & $R^{2}$ \\
\hline Wing length & $-0.31 \pm 0.14(0.03)$ & 0.12 & $-0.19 \pm 0.18(0.31)$ & 0.00 & $-0.28 \pm 0.36(0.44)$ & -0.03 \\
Tarsus length & $-0.26 \pm 0.15(0.08)$ & 0.07 & $-0.03 \pm 0.20(0.87)$ & -0.07 & $0.07 \pm 0.30(0.81)$ & -0.07 \\
Body mass & $-0.22 \pm 0.14(0.12)$ & 0.06 & $-0.16 \pm 0.21(0.45)$ & -0.04 & $-0.28 \pm 0.43(0.52)$ & -0.06 \\
Throat patch height & $-0.18 \pm 0.14(0.20)$ & 0.02 & $0.11 \pm 0.20(0.59)$ & -0.05 & $0.13 \pm 0.31(0.68)$ & -0.06 \\
Throat coloration & $0.23 \pm 0.16(0.15)$ & 0.04 & $0.25 \pm 0.20(0.21)$ & 0.04 & $0.41 \pm 0.36(0.25)$ & 0.03 \\
Tail length & $-0.45 \pm 0.13(<0.01)$ & 0.26 & $-0.05 \pm 0.20(0.82)$ & -0.06 & $0.20 \pm 0.44(0.65)$ & -0.06 \\
Size of the white & $-0.35 \pm 0.14(0.02)$ & 0.16 & $-0.28 \pm 0.19(0.17)$ & 0.07 & $-0.21 \pm 0.30(0.50)$ & -0.04 \\
$\quad$ & & & & & &
\end{tabular}

${ }^{1}$ Sample size reduced to 25,12 , and 10 , respectively. 
552

553

554

555

556

557

558

559

560

561

562

563

564

565

566

567

568

569

570

571

572

573

574

575

576
Figure legends

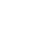

(n)

.

.

7

\section{8} 9 60

1

2

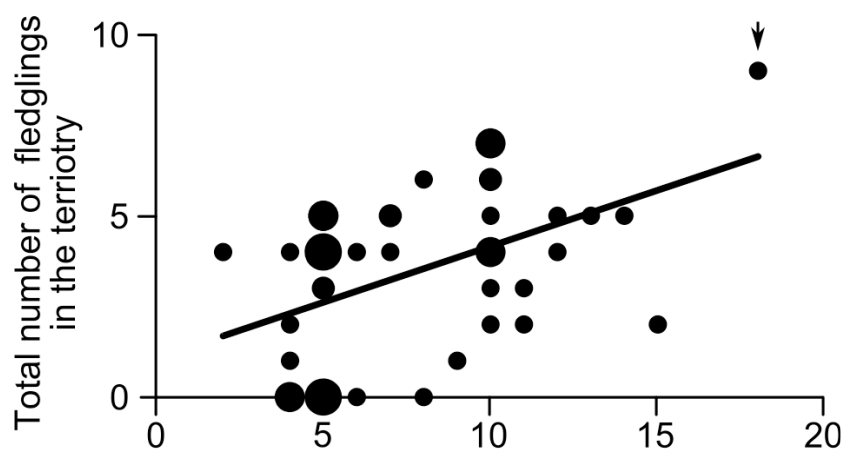

Territory quality 


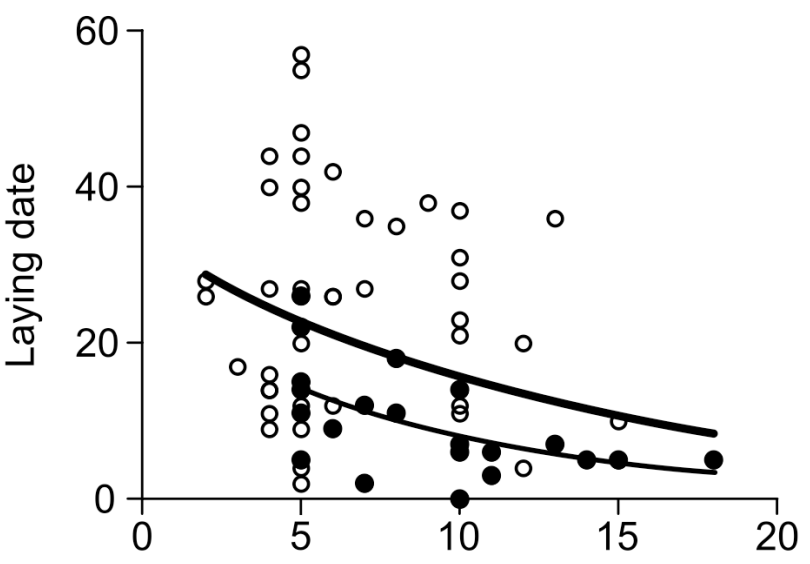

592

593

Fig. 2 Relationship between male territory quality and the laying date $(12$ April $=0)$ of his

597 mate. Filled and open circles indicate ASY and age-unknown males, respectively. Regression curves, which were predicted by GLM with quasi-poisson distribution, are

599 shown (broad line: ASY and age-unknown males; narrow line: ASY males only)

600

601 


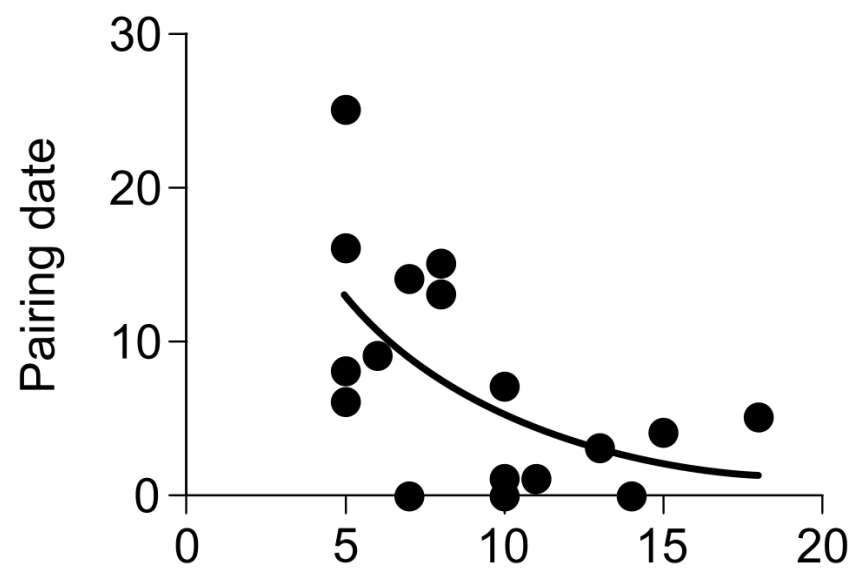

617

618

619

620 Fig. 3 Relationship between male territory quality and pairing date $(31 \mathrm{March}=0)$ in ASY

621 males. A regression curve, which was predicted by GLM with quasi-poisson distribution, is 622 shown 